\title{
Useful surgical instruments for the resection of subaortic stenosis
}

\author{
Yuki Tanaka, MD, ${ }^{\mathrm{a}}$ Takashi Miyamoto, $\mathrm{MD}, \mathrm{PhD},{ }^{\mathrm{a}}$ Kazutomo Minami, $\mathrm{MD}, \mathrm{PhD},{ }^{\mathrm{b}}$ and \\ Kagami Miyaji, $\mathrm{MD}, \mathrm{PhD},{ }^{\mathrm{c}}$ Shibukawa and Sagamihara, Japan
}

Myotomy or myectomy for hypertrophic subaortic stenosis (SAS) and membrane resection for discrete SAS have been performed widely. ${ }^{1,2}$ Although some previous studies have demonstrated problems, such as a high recurrence rate and postoperative aortic regurgitation, there is no alternative to the operation in patients with a high pressure gradient. ${ }^{3,4}$ Furthermore, it is difficult for individual cardiovascular surgeons to gain sufficient experience outside highvolume centers because of the low incidence of surgical cases. To perform this difficult surgical technique more easily, we use made-to-order surgical instruments for resection of the membrane or muscle in patients with SAS. These surgical instruments are custom-made for the depth and target angle in the transaortic approach. We report their usefulness in a sample surgical case of SAS.

\section{TECHNIQUE AND RESULTS Instruments}

Here we describe the special features of surgical instruments for resection of the subaortic region (Figure 1). The scalpel has a total length of $22 \mathrm{~cm}$ and an angle of $140^{\circ}$ at $3 \mathrm{~cm}$ from the tip. It is used by attaching an edge to the tip. The scissors has a total length of $25 \mathrm{~cm}$ and an angle of $160^{\circ}$ right in the middle. The retractors have a total length of $30 \mathrm{~cm}$ and an angle of $120^{\circ}$ at $5 \mathrm{~cm}$ from the tip with a groove.

\section{Case}

An 11-year-old girl had a diagnosis of discrete SAS with constrictive pericarditis. Although she could not report subjective symptoms because of severe mental disability, we elected to perform pericardiotomy with resection of the subaortic membrane in light of the high peak instantaneous left ventricular outflow tract (LVOT) gradient of $80 \mathrm{~mm} \mathrm{Hg}$. The operation was performed through a median sternotomy. After pericardiotomy, the patient was cooled to $32^{\circ} \mathrm{C}$ for

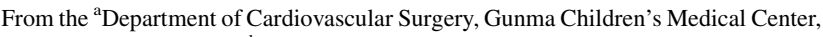
Shibukawa, Japan; the bepartment of Cardiovascular Surgery, Kitakanto Cardiovascular Hospital, Shibukawa, Japan; and the ${ }^{\mathrm{c} D e p a r t m e n t}$ of Cardiovascular Surgery, Kitasato University School of Medicine, Sagamihara, Japan.

Disclosures: Authors have nothing to disclose with regard to commercial support.

Received for publication March 17, 2015; accepted for publication March 26, 2015; available ahead of print May 2, 2015.

Address for reprints: Yuki Tanaka, MD, Department of Pediatric Cardiac Surgery, Gunma Children's Medical Center, 779 Shimohakoda, Hokkitsumati, Shibukawa,

Gunma 377-8577, Japan (E-mail: tfjgp484@yahoo.co.jp).

J Thorac Cardiovasc Surg 2015;150:421

$0022-5223 / \$ 36.00$

Copyright (c) 2015 by The American Association for Thoracic Surgery

http://dx.doi.org/10.1016/j.jtcvs.2015.03.062
}

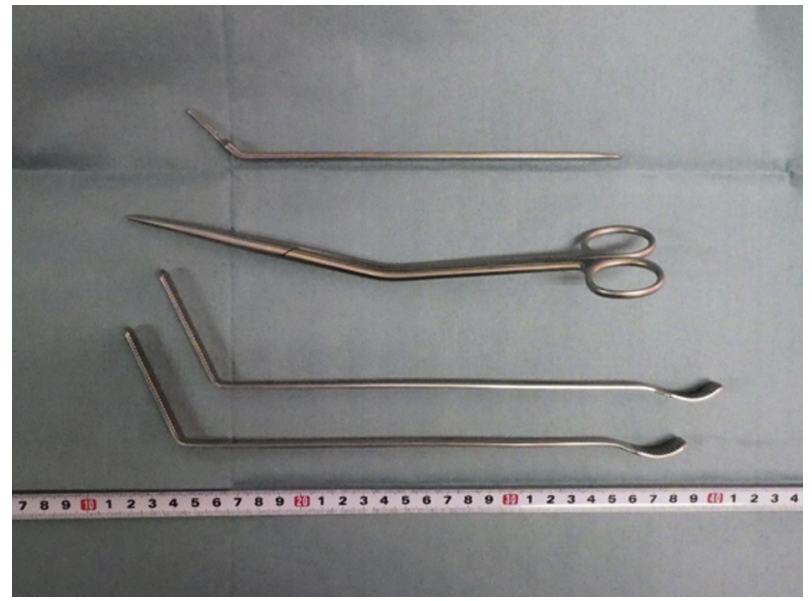

FIGURE 1. Photograph of our made-to-order surgical instruments. From top to bottom, this figure shows a scalpel, an angled scissors, and retractors.

cerebral protection under cardiopulmonary bypass and subsequent cardiac arrest. After aortotomy, the subaortic region was excellently exposed with angled retractors with a groove (Figure 2, A). The obstructive fibrous membrane, which appeared on the LVOT (Figure 2, B), and a part of the septal muscle were resected with a scalpel and scissors angled to enter the septal muscle at a shallow angle (Figure 2, $C$ and $D$ ). We confirmed passage of the diameter dilator $(15 \mathrm{~mm})$. After we confirmed that there was no aortic regurgitation and no injury of the aortic valve, the incision of the aorta was closed. The postoperative peak instantaneous LVOT gradient was decreased, and this patient was discharged from the hospital on postoperative day 11 .

\section{DISCUSSION}

Although early surgical repair of SAS is associated with a significant recurrence risk and aortic regurgitation progression, surgical intervention is required in patients with a high LVOT gradient. ${ }^{2}$ LVOT obstruction repair by the transaortic approach is difficult because of the small exposure and angle of approach. This approach, however, is necessary to avoid aortic valve injury, ventricular septal perforation, and impulse conduction defect. We therefore sought optimized instruments that would decrease the risk of surgical complications. The surgical instruments that we describe in this report have been adjusted several times before reaching their final form. The area and the depth of resection may vary in each case; however, we believe that this challenging surgical procedure is performed more simply and safely 


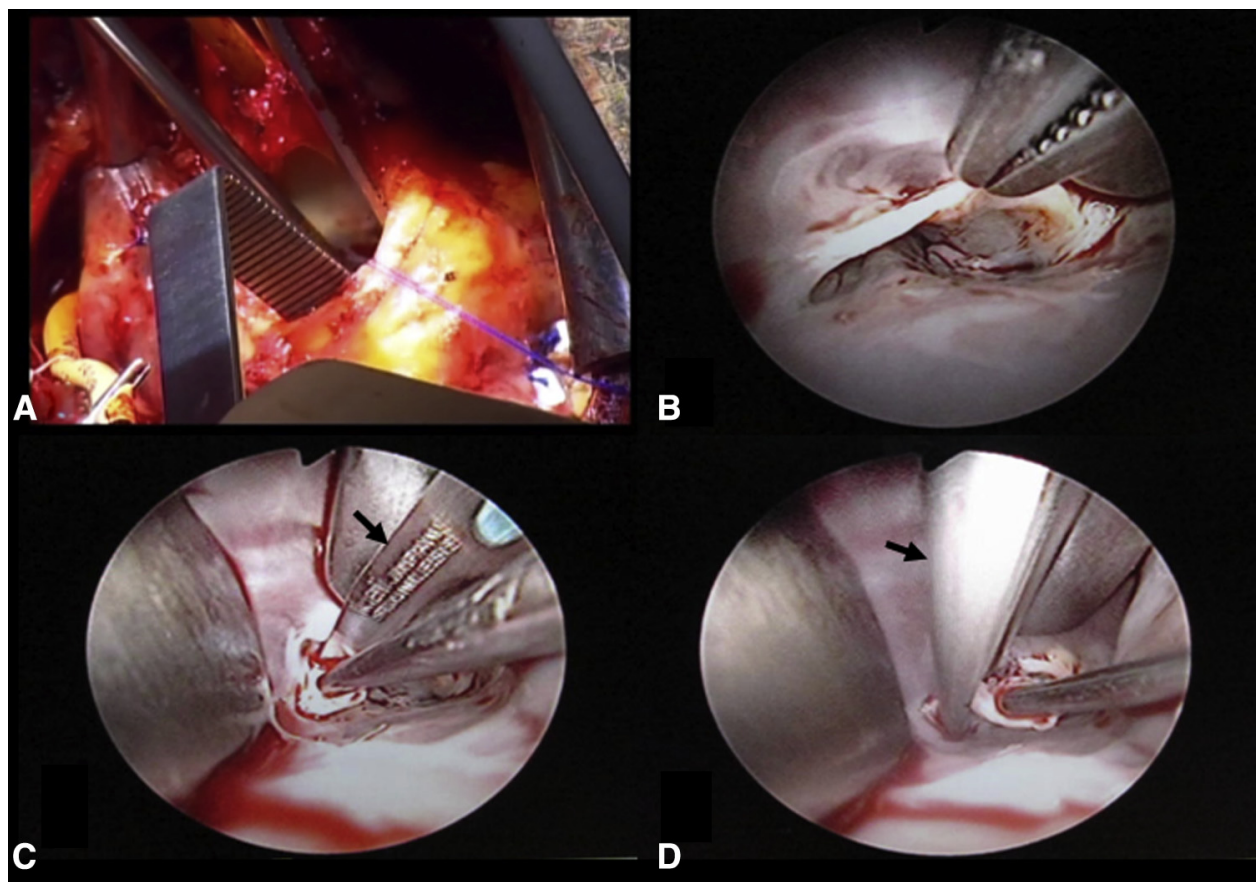

FIGURE 2. Intraoperative images. A, Exposure is obtained with angled retractors. B, Intraoperative endoscopy showing the subaortic membrane. C, An endoscopic image showing resection of the subaortic membrane with an angled scalpel (black arrow). D, Resection of the subaortic membrane with an angled scissors (black arrow).

with such devices. We hope for further development of similar useful devices in cardiovascular surgery.

\section{References}

1. Morrow AG, Brockenbrough EC. Surgical treatment of idiopathic hypertrophic subaortic stenosis: technic and hemodynamic results of subaortic ventriculomyotomy. Ann Surg. 1961;154:181-9.
2. Douville EC, Sade RM, Crawford FA Jr, Wiles HB. Subvalvular aortic stenosis: timing of operation. Ann Thorac Surg. 1990;50:29-33; discussion 33-4.

3. Ashraf H, Cotroneo J, Dhar N, Gingell R, Roland M, Pieroni D, et al. Long-term results after excision of fixed subaortic stenosis. J Thorac Cardiovasc Surg. 1985; 90:864-71

4. Hirata Y, Chen JM, Quaegebeur JM, Mosca RS. The role of enucleation with or without septal myectomy for discrete subaortic stenosis. J Thorac Cardiovasc Surg. 2009;137:1168-72.

\title{
Repair of anomalous aortic origin of coronary arteries with combined unroofing and unflooring technique
}

\author{
Hagi Dekel, MD, Edward J. Hickey, MD, Jack Wallen, MD, PhD, and Christopher A. Caldarone, MD, \\ Toronto, Ontario, Canada
}

\footnotetext{
From the Division of Cardiovascular Surgery, Hospital for Sick Children, Labatt Family Heart Center and University of Toronto, Toronto, Ontario, Canada.

Disclosures: Authors have nothing to disclose with regard to commercial support.

Received for publication Dec 1, 2014; revisions received April 17, 2015; accepted for publication May 3, 2015; available ahead of print June 4, 2015.

Address for reprints: Christopher A. Caldarone, MD, The Hospital for Sick Children, 555 University Ave, Suite 1525, Toronto, ON M5G 1X8, Canada (E-mail: chris caldarone@sickkids.ca).

J Thorac Cardiovasc Surg 2015;150:422-4

$0022-5223 / \$ 36.00$

Copyright (c) 2015 by The American Association for Thoracic Surgery

http://dx.doi.org/10.1016/j.jtcvs.2015.05.013
}

See related commentary on pages 425-6.

Anomalous aortic origin of a coronary artery (AAOCA) is a congenital anomaly in which a major coronary artery arises from the atypical sinus of Valsalva and commonly courses within the aortic wall (intramural) or between the great arteries before reaching its normal epicardial distribution. AAOCA predisposes affected persons toward hemodynamic collapse during or shortly after strenuous exercise. 